\section{From Rhetorics To Practice: Implementation Of Technological Innovation Within Spanish Public}

\section{Service Media}

\section{David Fernández-Quijada}

\section{Montse Bonet}

Universitat Autònoma de Barcelona, Spain
European Broadcasting Union, Geneva, Switzerland
Roberto Suárez Candel

European Broadcasting Union, Geneva, Switzerland

\section{Luis Arboledas}

Universidad de Granada, Spain

\section{ABSTRACT}

In the context of media and Information Society policies, there has been profound controversy in Europe with respect to the legitimate use of new technologies by public service media. Through qualitative interviews and policy documents analysis with a case study, this article illustrates how three Spanish public service media organizations apply technological innovations in order to successfully achieve their public service remit; the article thereby provides one of the first studies of innovation management in this field. Lessons from this paper include the difficult accountability of innovation, the non-formal nature of its practice, the central role of techno-enthusiasts and the bureaucratic problems of developing open innovation practices.

\section{KEYWORDS:}

innovation policy, media innovation, media management, media policy, public service media, Spain

The Journal of Media Innovations 2.2 (2015), 23-39.

DOI http://dx.doi.org/10.5617/jmi.v2i2.845

http://www.journals.uio.no/index.php/TJMI

(c) David Fernández-Quijada, Montse Bonet, Roberto Suárez Candel, and Luis Arboledas 2015 


\section{INTRODUCTION}

For many years, public broadcasting was understood as being associated with a particular technology that facilitated the dissemination of messages in accordance with the one-to-many broadcasting model. In the analogue era, the pace of technological innovation was slow and the arrival of FM to radio or colour images to television was not a traumatic experience for broadcasters.

Despite the fact that liberalisation and the arrival of the private sector in broadcasting had little to do with digitalisation (Moe, 2007), the latter did represent a new angle and a set of new business opportunities, thanks to the packaging and delivery of content in different platforms. That is how technology has acquired a prominent position in today's broadcasting environment.

In the last decade, the central impact of technology on broadcasting companies has also been reflected by increasing research interest on the topic. Public service media (PSM) are the operators where the attention has been focused on. While some authors and organisations question the intense use of new technologies by a public broadcasting service (ACT, EPC, \& AER, 2004), and even its own exis- tence (Jacka, 2003) or its unlikely future (Tracey, 1998), most of them are in favour of an active role of these broadcasters (Brevini, 2010; Debrett, 2009; Suárez Candel, 2012), as reflected in specific case studies (Van den Bulck, 2008; Whittle, 2004), including Spain (Bonet, Fernández-Quijada, \& Ribes, 2011; Prado \& Fernández, 2006), the home country of the organisations analysed in this study.

In general terms, research on technological innovation and media is still in its infancy (Storsul \& Krumsvik, 2013). Its actual importance in the sector is not reflected in researchers' interest, and the topic is clearly under-theorised. There are no established methodologies for its study and the debate on alternative theories to approach the issue has arisen (Rogers \& Sparviero, 2011). One of the few studies on innovation and public service media is that of Donders et al. (2012) on Flanders. The article joins government rhetorics on innovation and their derived policy actions through the public service media. The results illustrate how the traditional role of PSM as drivers of innovation and the neoliberal position in favour of market-led innovation causes an "in the middle" position with few policy choices. More specific is Cunningham's work (2009) on the innovation units created within Aus- tralian and British PSM, focusing not only on technology but also on programming and audiences. A similar approach is taken by Medina et al. (2011) for the case of the Catalan public broadcaster, identifying some key features to innovation success: reasonable funding, effective leadership, coordination between old and new media, coordination between creative and technological personnel and the development of this strategy not through an internal innovation unit, but rather through a separated company.

The main aim of this article is to study the relationship between technological innovation and public service media by means of a Spanish case study. The selected cases are those of Radio Televisión Española (RTVE), Corporació Catalana de Mitjans Audiovisuals (CCMA) and Radio Televisión de Andalucía (RTVA). The first is the national public service broadcaster whereas the two latter ones are the PSM organisations of the two most populated regions - Catalonia and Andalusia; they have the biggest budgets, the highest number of employees and the most comprehensive array of services among the thirteen Spanish regional public service media organisations (Table 1). We are dealing, then, with a strategic choice, which, at the 


\begin{tabular}{|c|c|c|c|c|c|}
\hline \multicolumn{6}{|c|}{ Selected cases (2012 data) } \\
\hline $\begin{array}{l}\text { PSM organisa- } \\
\text { tion }\end{array}$ & $\begin{array}{c}\text { Population } \\
\text { served (mil- } \\
\text { lions) }\end{array}$ & $\begin{array}{c}\text { Budget } \\
\text { (€ million) }\end{array}$ & Staff (FTE) & TV Services & Radio Services \\
\hline RTVE & 46.8 & 937.2 & 6,319 & 6 channels & 6 stations \\
\hline CCMA & 7.5 & 348.4 & 2,571 & 4 channels & 10 stations \\
\hline RTVA & 8.4 & 219.7 & 1,567 & 2 channels & 4 stations \\
\hline
\end{tabular}

same time, reinforces the external validity of the case study (De Vaus, 2001).

As innovation can be studied from multiple perspectives, the focus of this article lies on two specific issues: first, the relationship between technological innovation and PSM remit; second, the management of innovation within these organisations. The research questions that guided this research were intentionally general:

(RQ1) What is the role of innovation within public service media organisations vis-à-vis what it should be by law?

This first question deals with the differences between the role assigned to innovation within PSM by regulations and norms and its actual role as seen by the managers responsible for their daily operation.

(RQ2) How do public service media manage technological innovation within the organisation?

This second question focuses on actual and basic operative practices within the innovation units, such as their organisation, their links to other units within these operators, their relationships with external stakeholders, etc. 


\section{THEORETICAL FRAMEWORK: PSM AND} INNOVATION

In the field of media, public service (originally limited to radio and television activities) has usually been defined by means of identifying a set of values and objectives that were attributed to the provided contents (what), to the operators of the service (who), to their performance (how) and to the availability/reach of the offer (where, whom). In addition, the definition has often included the societal functions to be played by public service. These are connected with the expected effects and impact resulting from the achievement of the values and objectives mentioned.

In the last two decades, innovation has emerged as one of the most recent values assigned to these organizations. Thus, the current debate concerning public service in the media is essentially focused on their operational limits and the impact of PSM on the market. The major conflict not only includes the release of additional television or radio channels, but also especially the use of new distribution platforms such as the Internet and the development of online and mobile services.

The discussion arises because of the different and even opposite expectations that both public and commercial players have with regard to their opportunities for development in the new media context. Commercial operators consider that new online and mobile services belong exclusively to their scope of activity. These are seen as their natural development areas and essential sources of new revenues, which will guarantee the viability of their businesses in a more fragmented and abundant market where competition and income evolve inversely. Consequently, the provision of those services by public operators is considered by commercial operators as a major barrier for the health and growth of their business.

On the other hand, public service media have been innovators and pioneers for many years (Ariño \& Ahlert, 2004; Jakubowicz, 1999; Nissen, 2006) and consider they are justified in using new technical tools to reach the citizens they serve. As they are not constrained by economic (profit) results and/or other market interests, public media have been "flag-ships" of innovation and they have contributed to the deployment of new technologies and to the creation of new contents and formats (Debrett, 2009).

The organisational changes currently experienced by PSM are the result of their adaptation to changes in the market in the form of new technolo- gies, new services, new competitors and new audience behaviours. The management of this process reveals a degree of tension between the public interest of their activities and the need to efficiently allocate the increasingly limited financial resources at their disposal. It is the well-known organisational ambidexterity (Raisch \& Birkinshaw, 2008; Raisch et al., 2009), or the need to balance product and service innovation (exploration) and integration to achieve greater efficiency (exploitation) (Baumann, 2013). At the organisational level, this poses the "central problem of balancing the gains and costs of synchronising the structures of fully or partially autonomous organisational units in a situation of complexity and uncertainty" (Baumann, 2013, p. 81). Innovation units tend to autonomy in order to avoid the everyday life constraints but at the same time some coordination is needed in order to integrate their contributions and avoid excessive isolation.

In this dual scenario, innovation has quickly become a must in public service narrative; for example, it is one of the six core values of PSM as defined by the European Broadcasting Union (EBU, 2012). Innovation is also the new narrative for public media in the proposal by Goodman (2013, p. 214), especially in the United States, where "the principle 
narratives for public service media can all be characterized as market failure stories".

However, innovation is not a comfortable term for most PSM institutions; it is a relatively new idea to cope with and no standards have been set regarding its implementation within these organisations despite the consumer-centered public value tests developed for innovative services in some countries (Donders \& Moe, 2011).

As can be seen, innovation seems to mean many different things. In this paper, the focus is on the process of content production and distribution within public broadcasters and the structural conditions around it. Given the specific conditions of this kind of organisations and their special social responsibility, the analysis can help to deepen their role and empirically dig further into how it is being shaped by practitioners.

\section{METHOD}

The article is based on a literature study, document analysis and in-depth interviews with practitioners. The literature review allowed for establishing the state of the art of the topic, identifying the main gaps. The document analysis consisted of the review of legal acts and policy documents from the national and regional governments of Catalonia and Andalusia. This included all of the laws related to the broadcasting sector and the so-called Information Society issued from the 1980s: from European to national and regional policy documents and from innovation - often together with science - to broadcasting. In all of these documents, references to the term "innovation" were searched, with a view towards trying to understand its definition - if available -, its broader context and its relationship to media.

After that, and taking the public service broadcasting theories as the main theoretical framework, together with that of technological innovation, the views of the top managers of innovation issues in those organisations were explored through a series of nine semi-structured interviews (Table 2). Interviewees included both engineering and content management profiles; all of them were responsible for new technological development within their organisations. Except one done by telephone, all interviews were conducted face-to-face by two interviewers and took approximately one-and-a half hours. All were held between March and May 2012 in the facilities of these organisations in Madrid, Barcelona and Seville. The questionnaires of the interviews were organised around four areas: the nature of innovation within PSM, the institutionalisation of innovation, the interaction between the engineering and the content branches of those corporations, and external partnerships.

The design of this analytical model is somewhat different from the earlier work of Donders, et al. (2012), its clearest point of reference. First, it focuses on the views of top managers of innovation within PSM organisations and not on all of the stakeholders. Second, the geographical scope is different; although Spain and Flanders are usually considered part of the same European public service broadcasting tradition, the late transition to democracy in Spain, with respect to other Western European countries, has marked the shape and attitude of public broadcasting in this country (Fernández-Quijada \& Arboledas, 2013). This is clearly reflected in the resources allocated to public service media: according to the most recent data of 
Table 2.

Innovation managers interviewed

\begin{tabular}{|c|c|c|c|c|c|}
\hline Expert & PSM & Unit & Position & Place & Date \\
\hline Ignacio Gómez & RTVE & Rtve.es & $\begin{array}{l}\text { Entertainment Contents } \\
\text { Director }\end{array}$ & Barcelona & $15 / 03 / 12$ \\
\hline Ferran Clavell & CCMA & TVC & $\begin{array}{l}\text { Head of Interactive Services } \\
\text { at } \mathrm{TV}_{3}\end{array}$ & $\begin{array}{l}\text { Esplugues de } \\
\text { Llobregat }\end{array}$ & $16 / 03 / 12$ \\
\hline Marc Vicens & CCMA & $\begin{array}{l}\text { Catalunya } \\
\text { Ràdio }\end{array}$ & Innovation Director & Barcelona & $05 / 04 / 12$ \\
\hline Amadeu Gassó & CCMA & TVC & $\begin{array}{l}\text { Head of Operations and } \\
\text { Production }\end{array}$ & Sant Joan Despí & $10 / 04 / 12$ \\
\hline José Enrique Zamorano & RTVA & RTVA & Technical Director & Seville & $20 / 04 / 12$ \\
\hline Ricardo Villa & RTVE & Rtve.es & Interactive Media Director & Madrid & $16 / 05 / 12$ \\
\hline Charo Marcos & RTVE & Rtve.es & News Contents Director & Madrid & $16 / 05 / 12$ \\
\hline Pere Vila & RTVE & - & $\begin{array}{l}\text { Planning and Technological } \\
\text { Innovation Director }\end{array}$ & $\begin{array}{l}\text { Pozuelo de } \\
\text { Alarcón }\end{array}$ & $16 / 05 / 12$ \\
\hline Antonio Manfredi & RTVA & - & Interactive Media Director & $\begin{array}{l}\text { Seville (by } \\
\text { phone) }\end{array}$ & $18 / 05 / 12$ \\
\hline
\end{tabular}

the EBU (2014), Spain had the lowest percentage of GDP (0.08\%) devoted to its national public service media in Western Europe, and ranked $37^{\text {th }}$ of 41 markets across Europe. Meanwhile, Belgium's spending on its PSM organisations (0.20\% of the GDP) ranked it in the $15^{\text {th }}$ position in the same ranking. Third, academic research into technological innovation in broadcasting is still limited and, as in the aforementioned article, usually focuses on single case studies, thus leaving very little room for comparative research. In this article, a comparative approach is adopted among different media organisations within a single country. Moreover, both studies share the interest to join political discourse on public service and innovation with reallife practices of these media. In this sense, the aim of this article is to shed new light on this topic and contribute to the broader debate concerning innovation and public service broadcasting. Additionally, this article offers one of the first approaches to innovation within public service media organisations in Spain.

A final methodological consideration must be stated. As the methodological design of this research included interviews with practitioners who were not always familiar with the theoretical discussion on innovation, an operationalisation of 
this concept was seen as necessary. In this context, while the daily work of these practitioners was focused on developing new products and services, this research project was oriented towards their daily practices in the development of these new services. This made it quite obvious that the classic dichotomy between product innovation and process innovation could be useful, and so this framework was used when approaching the informants (European Commission, 2004; Fagerberg, Mowery, \& Nelson, 2005; OECD, 1995).

\section{BACKGROUND: INNOVATION AND COMMUNICATION POLICY RHETORIC}

The relation between technological innovation and public service media should bear in mind the broader context of national and regional public policies; not only broadcasting policies but also more general Information Society policies should matter (Harrison \& Wessels, 2005). In policy and regulation documents, innovation and media started to appear together in Spain in the first decade of this century. That is, innovation as a concept is usually linked to technology and, basically, to digital technology, Internet and telecommunications networks; in economic and social terms, it often appears alongside modernisation and the creation of employment, wealth and social welfare as defining norms.

A common political decision makes quite evident to what extent innovation becomes a mainstream idea: in that decade, the term "innovation" was included in the name of some government departments in Spain (in 2008), Catalonia (since 1980) and Andalusia (in 2001), stating that its aim was to propel the economy and change the production model of the Spanish economy, from the tradi- tional one based on construction, tourism, etc., to a new one, that of the Knowledge Society.

In the broadcasting sector, the different norms and corporate documents studied do not define innovation. Often, it is not clear if they are referring to technological or content innovation, so the concept entails a lot of ambiguity.

Given its importance, it may be expected that innovation appears in the main regulatory documents. That is not always the case and sometimes the concept simply cannot be found in basic norms like the General Audiovisual Communication Act of 2010 (BOE, 2010), the keystone of current Spanish broadcasting policies.

It is easier to find innovation as an access path to the Information Society, related to the dissemination of ethical values as a public service remit and commonly linked to content innovation. For example, it is mentioned in some recent laws for regional media, in the corporate sites of PSM organisations, in some style handbooks of the same broadcasters and in two specific laws: one in Catalan audiovisual media (DOGC, 2005, e.g. articles 26-3.k, 111-2.d and 124.b) and the other of Spanish public service media RTVE (BOE, 2006, article 3.2p; BOE, 2009, article 9.1-j). 
At the same time, there are strong similarities in the definition of public service found in national and regional norms; they include its conception as an essential service, based on the promotion of pluralism, identity and cultural diversity, with a broad range of programmes for any kind of public, covering all of their necessities through all the genres. Public service is also linked to digital technology and the Information Society. For example, RTVE has to stimulate digital and multimedia creation as a contribution to the development of Spanish and European cultural industries - e.g. BOE (2006), article 2.1 and 3.3 and RTVE (2007), article 30. With this aim, the corporation has to be an active participant in technological progress, using different distribution technologies and developing new interactive services.

Taking the Lisbon Agenda for 2000 as a reference, in the last two decades innovation has gradually achieved the central position in Spain it already had in some neighbouring countries (Bonet, Arboledas, \& Fernández-Quijada, 2013). In the context of European plans, specific programmes were developed in Spain, such as the Plan Avanza (Advancement Plan, 2005-2010), the Estrategia Estatal de Innovación (National Innovation Strategy, 2010) or Plan Avanza2 (Advancement Plan 2, 2011-2015).
The measures adopted in the last two decades have allowed for a positive development of the Spanish innovation system although some problems still remain: the dispersion of competences between different government bodies, the limited participation of private companies in public $\mathrm{R}+\mathrm{D}$ programmes and the difficult transfer of results from research to market (Benavides Velasco \& Quintana García, 2008). It seems difficult to overcome these problems with the current economic-crisis scenario. According to ICONO (R+D+I Spanish Observatory) ${ }^{1}$, the Spanish budget in $\mathrm{R}+\mathrm{D}$ grew until 2009, when it reached its peak, and then it decreased in 2012 to levels similar to those of 2005-2006.

1 http://icono.fecyt.es/indicadores/Paginas/default. aspx ind $=3$ \&idPanel $=1$.

\section{ANALYSIS: HOW PSM MANAGE INNOVATION}

As has been seen, PSM are obliged by their remit - and above them, by the broadcasting laws and norms - to lead technological innovation. However, the way this remit is implemented and managed varies among organisations, as can be observed in each of the areas of enquiry. RQ1 was focused on the role assigned to innovation within the PSM organisations analysed. The answers from the informants can be classified into three different areas: the consequences of including innovation in their remits, the culture of innovation developed within their organisations and, finally, the impact of budget constraints.

First, all interviewees, except one, agreed that their organisations have a special nature and remit. This last interviewee, with a content management profile, affirmed that there was no distinction between public and private firms when referring to innovation, although he recognised that public companies have more possibilities since they can experiment with services that are not economically profitable.

In practical terms, this creates an internal culture around innovation. This means that innovation is seen as something inherent to public servic- 
es: "It's up to us to push for certain things. I believe a pioneering role in certain areas is part of our DNA" (content manager, RTVE). Other managers expand this notion and consider that they also have an obligation to be a driving force of the technological industry, and some content managers highlight that the term "responsibility" is linked to their public service remit. One interviewee, an engineer, also mentions "quality". This is true for the CCMA (Corporació Catalana de Mitjans Audiovisuals), the organisation that, according to most of the interviewees, has pioneered many of the innovations introduced by Spanish broadcasters. This vision from practitioners is consistent with scholarly research, which in the last decade has demonstrated the innovative approach of this organisation to the new scenario characterised by digitalisation, convergence and the development of new applications (Bech et al., 2010; Bonet, M., Fernández-Quijada, D., \& Ribes, X., 2011; Fernández-Quijada \& Fortino, 2009; Medina et al., 2011; Prado \& Fernández, 2006). CCMA managers admit that they have been able to promote an "innovation culture" within the organisation that even has led to "a line where you're rapidly criticised when you don't innovate" (content manager, CCMA). Other commentators have also observed this cultural turn, for instance in Australia's ABC (Cunningham, 2012), and it is confirmed by the experience of informants in both RTVE and RTVA. In this latter case, the content manager also mentions that once this internal culture has been created, previous concerns such as physical distance -RTVA staff is distributed in 10 different buildings throughout the region- are no longer a problem. This view contrasts with a content manager from RTVE, who acknowledges that the fact of sharing facilities helps them to keep a more intense relationship with the Television Department than with the Radio Department. An engineer who manages innovation at RTVE goes even further and proposes that public service should lead the industry and help to generate technological clusters around it: "It's important to innovate because you help to develop your audience and the sector; you form well-prepared technicians for the country and if you're able to organise this as a cluster, you're also able to generate wealth for the country".

All of these developments contrast with the financial situation of these corporations. This idea emerged as the third factor to be considered when assessing the role of innovation within the organizations, all of whom have suffered sharp cuts in their funding since the economic crisis began: from
2010 to 2014, the decrease in budget for the broadcasters analysed went from $25.2 \%$ in RTVE to $34 \%$ in CCMA and $35.9 \%$ in RTVA, according to their annual accounts. The idea of what we suggest calling low-cost innovation also appears when one of our informants in Andalusia mentions that "I don't believe in expensive innovation, with a high cost.. that's not innovation". This sentence clearly points out the financial pressure suffered by innovation units, which have reduced their ambitions: quality is still a goal, but value for money has become a necessity and cost savings a justification for developing new services.

In this context, there is increasing pressure to become efficient, and the traditional trial and error system commonly applied for testing innovation is under attack. According to one of the content managers interviewed at RTVE, this is a mistake, since failure should be considered as part of the public service media contribution to other players in the market.

All of this conceptualisation of innovation within PSM organisations leads to the second research question, focused on the management of innovation, that is, how technological innovation is assumed within the organisation. Here, five areas emerged as being relevant: the level of formality of 
innovation, its relationship with the overall corporate strategy, the interaction between content and technology, the visibility of innovation and external partnerships.

In the first area, that of formality, the unanimous opinion is that innovation is basically nonformal. There can be some planning for specific projects but, generally speaking, the importance given to innovation in the remit and public discourse is not translated into specific formal practices. One possible explanation for this fact is given by a content manager at CCMA: "Our structures were made for making news, cutting tapes and driving mobile units, not for adapting our contents to new platforms". This view reflects the fact that the three organisations analysed have a traditional, powerful in-house structure, and that path-dependence is a key concern and an object of debate: history shapes each medium and each organisation but also makes it harder to change workflows and manage human resources according to current needs arising from innovation processes.

This casual appropriation of innovation can be seen in actual practices. For example, there are no formalised processes to detect innovation in broadcasting. Conferences and tradeshows are good events to keep in touch with innovators and iden- tify trends within the broadcasting industry. All of our informants also keep an eye on what other media, mainly international, are doing. This lack of formality is not always seen as negative, as one engineer at CCMA stated: "When you formalise too much, you become isolated". A corporation's colleague who manages content explains that innovation needs order, but also some chaos, to succeed. However, some time ago there was an Innovation Committee at CCMA, with an explicit methodology to develop innovation projects. This Committee disappeared in 2011 due to budget cuts and since then innovation appears by "spontaneous generation" (content manager, CCMA). The only current example of some formalisation is that of RTVE, which has the so-called Lab RTVE. There are four people permanently working in it (two IT technicians, one journalist and one designer) plus embedded journalists and producers for specific projects. In this Lab, ideas are welcome from every member of RTVE, who have the opportunity to pitch an idea to the Lab. One of its main aims is to blur the traditional boundaries between journalists, designers and technicians, which is a corporate differentiation established throughout the years.

Another example of this non-formal appropriation of technological innovations is the central role played by people. Many of the innovations implemented have arrived thanks to the determination of specific people. Two different profiles can be found at this point: first of all, that of managers who incorporated innovation into their discourse and their action. This explains why the Innovation Committee was launched at CCMA and why RTVE was so laggard in developing strategy for Internet, which did not arrive until the Interactive Media Department was created and put at the same hierarchical level as Radio and Television, thanks to the then President. The second profile is that of "techno-enthusiasts", key people in every department who are early adopters of technology and act as change agents and promoters of different technologies among their colleagues. One of the tasks of people at innovation units is to detect these technologists, guaranteeing more possibilities for the technology to succeed the internal level: "Our first mission is to detect who can lead, who has the willingness to overcome the obstacles of those opposed to change" (technical manager, RTVA). The reasons for opposing this constant innovation are mainly related to the fears of suffering "a cannibalistic process" (content manager, CCMA) through a loss of audience of their traditional programmes distributed through radio and television networks. 
The second relevant area highlighted by the informants was that of the attachment of innovation to the overall corporate strategy. At the institutional level, most of the innovation projects developed at all organisations analysed must be approved by the executive board or other relevant body. Also, due to the funding shortage faced by these corporations, some projects have been slowed down or directly shut down. In some cases, as in Andalusia, our informants talk about "missing opportunities". Regarding institutional constraints, one engineer at CCMA mentions the need to balance mid-term strategic investments with everyday needs, especially when funds are decreasing.

More worrying seems to be the lack of an institutional strategy. As one technical manager at RTVE explains, technological strategy is linked to the overall group strategy and this changes with every new chairman. Taking into account the politicisation of this traditionally short-lived position - an average of 2 years in the last 34 years - (Fernández-Quijada \& Arboledas, 2013), some obstacles arise in the planning stage within this area.

Third, another area of discussion was the interaction between the content and the technological branches of these media. In the three cases analysed, innovation is being developed within the
Interactive Media Department - the three institutions use the same terminology - at the same level as Radio and Television, the two traditional arms of these corporations. This internal organisation is recognised by the informants as essential to visualise that new media are as important as traditional media, although the amount of staff involved and the budgets assigned are clearly below the other two departments.

People involved in these interactive departments are mainly journalists and producers, but one also finds IT technicians and even designers. Lab RTVE, then, would be representative of these profiles. People in these departments are also responsible for contacting and stimulating colleagues in radio and television services in order to develop and manage new services.

Fourth, the visibility of innovation within the companies also emerged as a relevant issue. One of the technical managers from CCMA interviewed for this research highlighted that technology has to be transparent, mentioning, "Our unit is not here to create technology for technology's sake. We're here but it's fine if nobody talks about us". This vision is similar to that of one of his colleagues within the same organisation, who thinks, "Innovation is related to the world of ideas, of thought, of commu- nication, of schedules, of contents, of people and skills (...). Innovation in our field is not only related to technology, because technology has already done its work; it has led the process" (content manager, CCMA). In this sense, "technology helps to explain and to show the information... but it's always a tool for our contents" (content manager, RTVE); or, in plain English, "innovating is doing what you were doing but using new technologies" (technical manager, RTVE). At the same time, it "helps to rethink ideas constantly" (content manager, RTVE).

Paradoxically, once technology is seen as something more neutral and natural, it becomes more difficult for innovation to become visible, according to a content manager at CCMA. Visibility is also a key concern at RTVE, where the perception of one of the interviewees is that much of their work remains hidden for top managers because television is so big that it puts interactive services alongside radio as an invisible medium (Lewis \& Booth, 1989). This content manager mentions one specific example that she thought would happen: the HD transmission of the Olympic Games would be much more commented internally than the 16 simultaneous streams they were planning to offer, which really represents a dramatic increase of the value delivered for the audience, especially for minority 
sports with low media exposure.

Finally, the area that emerged as central in the management of innovation was that of external partnerships. Interactive departments have been born in an era when the number of employees is decreasing, so the number of employees in these departments is limited. Much of the work is outsourced or developed through collaborations. All of the informants see these alliances as natural and as examples of public-private partnerships. One of these collaborations mentioned has been organised around research projects, those at the European level but mainly at the national level, for instance through Plan Avanza, the Spanish flagship innovation plan. These partnerships also mean additional funding sources.

In the case of RTVA, two of the main partners are other public companies, Sandetel (Sociedad Andaluza para el Desarrollo de las Telecomunicaciones, i.e. Andalusian Society for the Development of Telecommunications) and Sadesi (Sociedad Andaluza para el Desarrollo de la Sociedad de la Información, i.e. Andalusian Society for the Development of the Information Society). These firms are also owned by the regional government and offer services such as Internet hosting or corporate networks to all public institutions in the region. This is not the case for RTVE, which buys technology but implements it with its own staff, nor for CCMA, which mainly relies on private firms, also in the implementation phase.

In the case of CCMA, and according to their idea to act as a driving force of the industry, the informants explained that they work with different universities and have even helped to develop new spin-off companies from them. The responsibility of public service companies in the management of public funds also move some small and mediumsized enterprises (SME) away from these corporations, since suppliers must have strict - and sometimes costly - processes of certification and accountability which sometimes these SMEs cannot afford. A second problem based on the public nature of these organizations emerged in the case of RTVA, since they are obliged by law to accept the cheapest offer received if it fulfils the minimum technical requirements. Obviously, this is not an incentive for the most innovative companies, which could push innovation far beyond expectations.

A last typology of partner that has recently appeared in this stage is that of multinational manufacturers of consumer electronics and software companies. It is necessary to negotiate with companies involved in fields like connected TV, videogames or Internet - YouTube and Facebook appeared frequently in most of the interviews - if these media want to offer their contents through these new outlets. Obviously, this involves less autonomy for PSM and more negotiation power for manufacturers.

It is worth mentioning that the collaboration between different media does also exist. For example, RTVE and CCMA have collaborated and exchanged experiences. RTVE also gets support from the EBU as an active member of this organisation. However, these collaborations could be increased through other forums such as the association of Spanish regional public service media (FORTA, Federación de Organismos de Radio y Televisión Autonómicos, i.e. Federation of Regional Organizations of Radio and Television). In this case, the difference in the size, budgets and even interest in innovation among its members has not helped them to share innovation practices. 


\section{DISCUSSION AND CONCLUSIONS}

Several conclusions can be drawn from the cases studied in this article. Regarding the first research question (RQ1), the translation of media and Information Society policies into actual practice appears to be extremely difficult when dealing with technological innovation. The more abstract level of the legislation states the strategic significance of technological innovation, but this is not usually clarified in more specific documents, such as contract-programmes or corporate norms. It can be said that the three cases studied illustrate a techno-scientific reductionism; innovation policies and the government that promote them are fascinated by technical development but they often fail in its operationalisation: innovation is seen as a kind of "black box" where the resources will "magically" become new, successful products and services in the market.

Additionally, there is no clear guidance for the implementation of innovation. That is why its accountability, an increasingly relevant feature of the PSM, is so difficult. At the same time, this also becomes the reason for clarifying the role, implementation and accountability of innovative services and applications.
Technological innovation as a concept has progressively appeared throughout the last decade in the remit of all the organisations analysed. From the interviews, it seems clear that innovation has been assumed to be an integral part of the public service remit and of its discourse. Two practical elements can be distinguished as proof of this assumption: first, the will to implement every type of technology that could be useful to the citizens they serve and, second, the adaptation of others' work to the needs, goals and mission of a public service.

It is also worth mentioning the fact that nearly all of the managers acknowledged that the special nature of PSM and its remit guide their decisions. Perhaps, surprisingly, in a country where the public service culture is clearly underdeveloped, values such as responsibility and quality are explicitly associated with technological innovation. This would make it easier for them to adapt to the requirements of a public value test if this tool were implemented in the future.

Additionally, failure is recognised by practitioners as a natural part of the innovation process, so it should be seen as a natural output of technological innovation policies. Regarding this issue, government rhetoric concerning the importance of innovation is not translated into specific economic funds, so it remains as a mere discursive argument. It is also necessary to highlight that political pressure and debates remain at the top managerial level but do not affect everyday work in innovation units. Other decisions taken by these managers, such as budget cuts, do have an effect on these units, which from their birth have been used to growing budgets. This situation confirms Baumann's (2013) observation about the delicate position of these autonomous units within larger corporate structures. Although this pressure has also led to offer more value for money, and processes should be driven by evidence, this conservatism can also unbalance the relationship between exploration and exploitation in favour of the latter.

If initially organisational ambidexterity within PSM seemed to be more inclined towards exploration due to the non-commercial nature of these organisations, their critical financial situation is now putting on the table the need to think more about exploitation, shifting from public- to marketoriented innovation. This also means that the distinctive role of PSM in driving innovations within the media field could be questioned. If confirmed by future developments, this shift poses serious doubts concerning the role assigned to PSM regarding innovation. Relying only on low-cost inno- 
vation could become counter-productive in political terms, diminishing the support for active PSM, since they could lose the opportunity to properly foster cutting-edge innovation.

In practical terms (RQ2), the management of this innovation has some common patterns: (a) In the absence of specific guidelines, technological innovation basically follows non-formal procedures, clearly aligning these media with the exploration side of innovation. (b) Although innovation is not formalised, in general terms this is not seen as a problem, and in some cases it is even assumed to be the natural way to achieve success. (c) It is heavily centred on people, since innovation often depends on personal initiatives. Although at the decision stage all of the process follows a top-down mechanism, ideas may arise from any member of the staff. (d) There is a limited number of external partners because of the bureaucratic process when outsourcing specific tasks. This responds to the necessary guarantees that a public service must apply to the investment of its funds, but it does not fit well with the dynamism of small start-ups, where many of the most innovative ideas arise. This is clearly seen as a handicap by the executives interviewed, and (e) there is no common strategy for television, radio and the new media.
Additionally, budget cuts also appeared in the daily management of innovation; it needs stable funding since many projects need mid- or longterm development (Dogruel, 2014) and they cannot be discontinued in the current competitive environment. As stated, in this scenario collaborations are seen as necessary. However, what could be seen as a natural partnership -that of different public service media organisations- has hardly been explored until now. But it would make sense, since all of them are publicly funded and collaboration would probably imply better value for taxpayer funds. On the contrary, it is also necessary to stress that innovation is also linked to the PSM function to act as a driving force of the local industry, thus contributing to the national economy. Originally applied to the traditional audiovisual industry cinema, radio and television -, in the current scenario this function can be extended into innovative IT companies that can offer these corporations new know-how and skills which are not currently available within these organisations, linking PSM to the idea of open innovation (Chesbrough, 2006). These partnerships can include third parties such as universities, increasing the value of collaboration and extending it into new areas, thus increasing its direct contribution to society. Open innovation as an industry driver becomes, then, a new case to justify PSM existence. In political terms, it also helps to link public service media with broader policy issues even at the European Union level, where innovation policy is becoming increasingly significant and has been placed at the heart of the Europe 2020 Strategy.

Some final lessons can be drawn from the findings of this article: Although technological innovation is assumed to be an integral part of the remit of public service media, its formalisation and translation into specific actions is difficult. Although managers agree that innovation needs some chaos to arise, the development of specific guidelines, not excessively bureaucratic, should be explored. The Lab RTVE seems relevant in this sense. Clearly, more research is needed in this area, as well as some time to assess its results, since innovation has only recently become an element to be considered within the remits of these media. At the macrolevel, the political discourse on innovation does not hide the actual practices and funding assignment, which contradicts that discourse. Then, the development of innovation is only fostered by public service media remit, which seems to be more effective than broadcasting laws. It also probably reflects the willingness of these corporations to be accountable 
and justify their funding by broadening their mission in an age of sharp cuts. Together with the need to find talent outside the organisation itself, these cuts are promoting the development of practices of open innovation, which has a positive effect on the developers, and fosters the local industry.

\section{REFERENCES}

ACT, EPC, \& AER (2004). Safeguarding the future of the European audiovisual market: White paper on the financing and regulation of publicly funded broadcasters. Brussels: Association of Commercial Television in Europe.

Ariño, M., \& Ahlert, C. (2004). Beyond broadcasting: The digital future of public service broadcasting. Prometheus, 22(4), 393-410.

Baumann, S. (2013). Adapting to the Brave New World. Innovative Organisational Strategies for Media Companies. In T. Storsul \& A. H. Krumsvik (Eds.), Media Innovations. A Multidisciplinary Study of Change (pp. 77-92). Göteborg: Nordicom/University of Gothenburg.

Bech J., Molina T., Vilaclara E., \& Lorente, J. (2010). Improving TV weather broadcasts with technological advancements: two cases from a 20 year perspective. Meteorological Applications, 17(2), 142-148.

Benavides Velasco, C. A., \& Quintana García, C. (2008). Generación de conocimiento tecnológico y políticas de innovación: dimensiones e interrelaciones [Technological knowledge generation and innovation policies: dimensions and interrelations]. Revista de economía mundial, 18, 283-297.
Bonet, M., Arboledas, L. \& Fernández-Quijada, D. (2013). Innovación tecnológica y servicio público: el abismo entre políticas y realidad. Derecom, 14. Retrieved from http://www.derecom.com/numeros/ pdf/bonet.pdf.

Bonet, M., Fernández-Quijada, D., \& Ribes, X. (2011). The Changing Nature of Public Service Radio: A Case Study of iCat FM. Convergence: the International Journal of Research into New Media Technologies, 17(2), 177-192.

BOE (2006) Ley 17/2006, de 5 de junio, de la radio y la televisión de titularidad estatal, Boletín Oficial del Estado, 134, 6 June. Retrieved from http://www. boe.es/buscar/act.php?id=BOE-A-2006-9958.

BOE (2009) Ley 8/2009, de 28 de agosto, de financiación de la Corporación de Radio y Televisión Española. Boletín Oficial del Estado 201, 31 August. Retrieved from http://www.boe.es/buscar/doc. php?id=BOE-A-2009-13988.

BOE (2010) Ley 7/2010, de 31 de marzo, General de la Comunicación Audiovisual. Boletín Oficial del Estado, 79, 1 April. Retrieved from http://www.boe.es/ buscar/act.php?id=BOE-A-2010-5292. 
Brevini, B. (2010). Towards PSB 2.0? Applying the PSB ethos to online media in Europe: A comparative study of PSBs' internet policies in Spain, Italy and Britain. European Journal of Communication, 25(4), 348-365.

Chesbrough, H. (2006). Open Innovation. The New Imperative for Creating and Profiting from Technology. Boston: Harvard Business School Press.

Cunningham, S. (2009). Reinventing television: the work of the 'innovation unit'. In G. Turner \& J. Tay (Eds.), Television studies after TV: Understanding television in the post-broadcast era (pp. 83-92). New York: Routledge.

Cunningham, S. (2012). The new normativity: the innovation imperative. Paper presented at RIPE@2012 conference, 5-7 September, Sydney (Australia). Retrieved from http://ripeat.org/wp-content/uploads/ tdomf/2926/Cunningham\%2opaper\%202012.pdf.

De Vaus, D. A. (2001). Research Design in Social Research. London: Sage.

Debrett, M. (2009). Riding the wave: public service television in the multi-platform era. Media, Culture \& Society, 31(5), 807-827.
DOGC (2005) Llei 22/2005, de 29 de desembre, de la comunicació audiovisual de Catalunya, 4543. Retrieved from http://portaldogc.gencat.cat/utilsEADOP/AppJava/PdfProviderServlet?versionId $=5$ 31253\&type $=01$

Dogruel, L. (2014). What is so Special about Media Innovations? A Characterization of the Field. The Journal of Media Innovations, 1(1), 52-69.

Donders, K., \& Moe, H. (Eds.) (2011). Exporting the Public Value Test. The regulation of public service broadcasters' new media services across Europe. Göteborg: Nordicom.

Donders, K., Ranaivoson, H., Lindmark, S., \& Ballon, P. (2012). Public broadcasters and innovation: A contested combination in Flanders. Innovation: Management, Policy \& Practice, 14(2), 265-277.

EBU (2012). Empowering Society. A declaration on the core values of public service media. Le GrandSaconnex: European Broadcasting Union. Retrieved from http://www3.ebu.ch/files/live/sites/ebu/files/ Knowledge/Publication\%2oLibrary/EBU-Empowering-Society_EN.pdf.

EBU (2014). Funding of Public Service Media 2014. Le Grand-Saconnex: European Broadcasting Union.
European Commission (2004). Innovation Management and the Knowledge-Driven Economy. Brussels: European Commission. Retrieved from ftp://ftp.cordis. europa.eu/pub/innovation-policy/studies/studies_innovation_management_final_report.pdf.

Fagerberg, J., Mowery, D.C., \& Nelson, R.R. (2005). The Oxford Handbook of

Innovation. Oxford: Oxford University Press.

Fernández-Quijada, D., \& Arboledas, L. (2013). The Clientelistic Nature of Television Policies in Democratic Spain. Mass Communication and Society, 16(2), 200-221.

Fernández-Quijada, D., \& Fortino, M. (2009). Servicio público y patrimonio audiovisual: el proyecto VideoActive [The VideoActive project: Television as public service and audiovisual patrimony]. El profesional de la información, 18(5), 545-551.

Goodman, E. P. (2013). Public service media narratives In. M. E. Price, S. G. Verhulst \& L. Morgan (Eds.), Routledge Handbook of Media Law (p. 193-215). Abingdon: Routledge.

Harrison, J., \& Wessels, B. (2005). A new public service communication environment? Public service broadcasting values in the reconfiguring media. $\mathrm{New} \mathrm{Me-}$ dia \& Society, $7(6), 834-853$ 
Jacka, E. (2003). "Democracy as Defeat". The Impotence of Arguments for Public Service Broadcasting Television \& New Media, 4(2), 177-191.

Jakubowicz, K. (1999). Public Service Broadcasting in the Information Society. Retrieved March 12, 2012 from http://www.waccglobal.org/en/19992key-issues-in-global-communications/834-PublicService-Broadcasting-in-the-Information-Society--. html.

Lewis, P. M., \& Booth, J. (1989). The invisible medium public, commercial and community radio. London: Macmillan.

Medina, M., Herrero, M., Llorens, C., \& Miralles, S. (2011). Implementation of innovation strategy: The case of CCRTV Interactiva. In Z. Vukanovic \& P. Faustino (Eds.), Managing Media Economy, Media Content and Technology in the Age of Digital Convergence (pp. 89-120). Lisbon/Podgorica: Media

XXI/International Academy for Media Management Podgorica.

Moe, H. (2007). Commercial services, enclosure and legitimacy. Comparing contexts and strategies for PSM funding and development. In G. F. Lowe \& J. Bardoel (Eds.), From Public Service Broadcasting to Public Service Media (pp. 51-69). Göteborg: Nordicom
Nissen, C. (2006). Public service media in the Information Society. Strasbourg: Council of Europe.

OECD (1995). The measurement of scientific and technological activities. Proposed guidelines for collecting and interpreting technological innovation data. Oslo manual. Paris: Organisation for Economic Cooperation and Development.

Prado, E., \& Fernández, D. (2006). The role of public service broadcasters in the era of convergence. A case study of Televisió de Catalunya. Communications \& Strategies, 62, 49-69.

Raisch, S., \& Birkinshaw, J. (2008). Organizational Ambidexterity: Antecedents, Outcomes, and Moderators. Journal of Management, 34(3), 375-409.

Raisch, S., Birkinshaw, J., Probst, G., \& Tushman, M. L. (2009). Organizational Ambidexterity: Balancing Exploitation and Exploration for Sustained Performance. Organization Science, 2O(4), 685-695.

Rogers, J., \& Sparviero, S. (2011). Understanding innovation in Communication industries through alternative economic theories: The case of the music industry. The International Communication $G a-$ zette, 73(7), 610-629.

RTVE (2007) Mandato-marco a la Corporación RTVE. Retrieved from http://www.rtve.es/contenidos/ documentos/MANDATO_MARCO_18_12_07.pdf
Storsul, T., \& Krumsvik, A. H. (2013). What is Media Innovation? In T. Storsul \& A. H. Krumsvik (Eds.), Media Innovations. A Multidisciplinary Study of Change (pp. 13-26). Göteborg: Nordicom/University of Gothenburg.

Suárez Candel, R. (2012). Adapting Public Service to the Multiplatform Scenario: Challenges, Opportunities and Risks. Working Papers of the Hans-BredowInstitute, (25). Hamburg: Hans-Bredow-Institute.

Tracey, M. (1998). The Decline and Fall of Public Service. Oxford: Oxford University Press.

Van den Bulck, H. (2008). Can PSB stake its claim in a media world of digital convergence? The case of the Flemish PSB management contract renewal from an international perspective. Convergence: the International Journal of Research into New Media Technologies, 14(3), 335-349.

Whittle, S. (2004). Public service broadcasting in the new media age: The BBC's experience. Trends in Communication, 12(1), 3-13. 